\title{
Headcounts on Steroids: A Lightweight Method for Evaluating Space and Furniture Use
}

\author{
Katherine Gerwig and Carolyn Bishoff \\ University of Minnesota Twin Cities, USA
}

\begin{abstract}
The study identified patterns of space and furniture use to inform planning and vision for the busiest library on the University of Minnesota Twin Cities campus. Library staff manually gathered headcount and user behavior data in Walter Library during the fall 2017 and spring 2018 semesters. Data was gathered three times a day, three days per week, during three weeks throughout the semester. The data included counts of people by furniture type and was augmented with time and location data. These data were combined with total seat counts by furniture type, room, and floor and compared across time and space. The instrument was updated and refined to improve data collection. Library users' furniture preferences changed drastically from room to room. We found that spaces with furniture and atmosphere designed for collaborative work were very popular, as were spaces designed for quiet, individual study. Furniture supportive of individual study were underutilized in rooms and areas more conducive to group or parallel study and vice versa. We want flexible spaces and a nimble decision-making process but have limitations due to the constraints of our historic building. The study has encouraged creative, user-centered thinking. The methodology is lightweight enough to repeat the study each semester and at the same time produces actionable information that have informed major decisions and a vision for our library space as a whole. The datasets we generated answered big picture questions about library use and informed individual decisions about the placement and use of pieces of furniture. Most importantly, the study has challenged many of our assumptions about how people use the library's spaces.
\end{abstract}

\section{Introduction}

The University of Minnesota Libraries are, like many libraries, moving from a collection-centered approach to library spaces to re-envisioning the library as an informal learning space. To that end, the largest libraries on campus have recently seen a massive reduction of the size of the reference collections housed on site to make space for additional student work areas and collaboration space. Just as libraries do collection analysis to ensure they are providing the resources their users need, it is important to understand user needs and behaviors in informal learning spaces as a means of ensuring those spaces provide the environment required to help our patrons accomplish the work they came to do.

Developing an understanding of user interactions with library spaces has prompted a number of userfocused studies in the library literature. The simplest method used to obtain baseline information on humanenvironment interactions is a passive observational study. ${ }^{1}$ Observational studies use a wide range of methods. They may include counts by room and furniture type or divide spaces into artificially defined zones. ${ }^{2}$ Observational studies can employ the use of paper maps, mobile apps, or even GIS mapping software. ${ }^{3}$

Observational studies often use a mixed-methods approach to create a more complete picture of user activity and perceptions, incorporating surveys, photo diaries, mapping exercises, or whiteboard comments. ${ }^{4} \mathrm{~A}$ mixed-methods approach can also provide qualitative information about what users want out of a space. ${ }^{5}$ Libraries have used a variety of methods to design learning spaces and gather feedback from potential users, including observations, interviews, usability tests, environmental scans, ideal space design exercises, and focus groups. ${ }^{6}$

Environmental psychology is the field of study devoted to the exchanges and interactions between people and their surroundings. Many of the methods used in environmental psychology can be employed to gain an understanding of library space use. Additionally, findings in environmental psychology provide the 
foundation for understanding the behaviors recorded in studies of library space. For instance, many observational studies of user behavior in library spaces show an occupancy rate of around $50 \%$. This phenomenon has been documented by environmental psychology researchers and appears to be quite robust. $^{7}$

Libraries sit at the intersection of learning theory, architecture, and placemaking. In addition to an awareness of environmental psychology, an understanding of the library as a cultural construct which brings a specific picture to mind is also useful when interpreting library space use data. Communal use of a space is the act of quietly being in a space with others while social use is the collaborative group work that produces some amount of noise and activity. While libraries are increasingly seeking ways to support social use, traditional study spaces are still highly desired. ${ }^{8}$ It has been recognized that libraries often find themselves struggling to fill a social need at the expense of their traditionally communal nature. ${ }^{9}$

Walter Library is a library on the University of Minnesota Twin Cities campus that has undergone a significant transition from collection storehouse to student learning space and contains many spaces that support collaboration, communal use, and semiprivate work. Opened to the public in 1924, Walter Library is the oldest library on campus. The lobby and second floor have marble walls, beautiful ornate ceilings, marble columns, and frescoes above the doorways. The library houses the physical science and engineering collections, but much of the collections were moved to storage during a renovation completed in 2002 . It has huge areas devoted to individual and group study space and is centrally located on campus, which contributes to the large numbers of students who use the library.

The ornate grandeur and historical status of these areas mean there are restrictions on what staff can and cannot do to modify the space. The major study areas on the second floor are huge rooms with vaulted ceilings. Two of these rooms contain heavy wooden tables that are hardwired into the floor and require a crane to move. Careful thought is required before asking to change things in Walter.

However, the space does require updates and thoughtful redesign. Over time, furniture was moved wherever there was space, not necessarily where students would find it valuable. Some spaces had been neglected because of the restrictions on moving the heaviest furniture or simply not knowing how to take the first step. There was not any data that helped to address these problems, guide decisions, or aid in determining priorities. Walter is large enough that it can provide both social and communal spaces desired by users, but striking a good balance had to be achieved by careful observation of the activity occurring in the spaces.

A data collection project was designed to gain a better understanding of how people are using the spaces and furniture in Walter Library so informed decisions could be made about the spaces and a more strategic and iterative approach to designing library spaces based on user needs could be taken.

\section{Method}

An observational method was used to establish an understanding of how the library spaces are used as a whole. We conducted headcounts organized by seating type, time, and area of the library to acquire more granular information than gate counts or room or nondescriptive headcounts could provide.

Counts were conducted during the fall 2017 and spring 2018 semesters along with a limited set of observations. Counts and observations were recorded 27 times throughout a semester: at 10:00 a.m., 3:00 p.m., and 8:00 p.m. on Tuesdays, Wednesdays, and Thursdays during the 5th, 9th, and 14th weeks of the semester. The building was divided into seven areas corresponding to a large room on the second floor or one of the lower levels. Each type of furniture in the building was identified and defined. Each group study room was identified. Special types of furniture and equipment were also defined to take more detailed observational data. These included:

1. Number of people sitting at computer stations and not using the library's computer (technology/equipment, behavior) 
2. Location of groups (behavior)

3. Orientation of people using standing tables (behavior)

4. Location of upright monitors (technology/equipment)

5. Number of upright monitors in use (technology/equipment)

Data was entered into a spreadsheet using a Google Form. Staff also had the option of using a paper form, which was entered into the Google Form at a later time. The data collector recorded the time of day and the area they were counting. They counted the number of people sitting at each type of furniture in the area and recorded the numbers under the correct furniture type. If there was no one using a type of furniture in the space or if the type of furniture was not present in the space at all, they recorded a 0 . The form prompted them for additional observations. Finally, the form for the area was submitted and a new form was started for the next area. The steps were repeated seven times until each public area was counted. Data collection for the whole building took 30 minutes or less.

The data were cleaned, filtered, and analyzed. Each row represented one count completed in one area of the building and included descriptive information about the time of day, day of the week, data collector, and a timestamp. Staff added descriptive $\mathrm{mm} / \mathrm{dd} /$ yyyy information to make the data sort chronologically. All the headcount and observational data were recorded in columns listed as furniture types, group study rooms, and observational categories. A working copy of the data was created and a separate dataset containing the total number of seats in each space was used to correct for collector error. The researchers made educated inferences in cases where the data did not add up. For instance, if a data collector counted 3 users at "tables with 5-6 seats" in an area where there were no "tables with 5-6 seats" but there were "tables with 4 or fewer seats," it was assumed that a mistake or misinterpretation occurred and we adjusted the count to the correct category. However, if we noted that 9 users were counted in a study room that only seats 5 , we left those data alone because they are more likely to represent accurate user behavior than a counting error. Once the data were clean, the headcount data and the dataset with the total number of seats by furniture type (a subset of which is in Table 1) were combined to calculate the number of unoccupied seats for each count. Frequency analysis was used to look at absolute numbers of users in each area and to calculate occupancy rates to compare usage across rooms and furniture types.

Tables 1 and 2: Total available seats

\begin{tabular}{|l|l|}
\hline Library area & Seats \\
\hline Great Hall (2nd floor) & 62 \\
\hline Reference Room (2nd floor) & 177 \\
\hline Quiet Study (2nd floor) & 152 \\
\hline SMART Learning Commons (2nd floor) & 78 \\
\hline Basement Level & 52 \\
\hline Sub-Basement Level & 41 \\
\hline Foundation Level & 42 \\
\hline Total & 604 \\
\hline
\end{tabular}




\begin{tabular}{|l|l|}
\hline Furniture type & Seats \\
\hline Soft chairs & 126 \\
\hline Long tables (7+ seats) & 231 \\
\hline Medium tables (5-6 seats) & 66 \\
\hline Small tables (4 seats or less) & 86 \\
\hline Study carrels & 34 \\
\hline Computer seats & 38 \\
\hline Standing-height tables & 18 \\
\hline "Brody" lounge chairs & 5 \\
\hline Total & 604 \\
\hline
\end{tabular}

The instrument was updated and refined to improve data collection. The first iteration of the instrument used during the fall 2017 semester divided the library into nine smaller areas rather than seven. The instrument was changed in the spring 2018 semester since no useful data came from dividing the larger rooms and contributed to more complicated data cleaning. The first iteration also did not include a room containing the SMART Learning Commons, which is a shared space that hosts tutoring and media production. SMART was included in spring 2018 counts. Finally, the second iteration of the instrument in spring 2018 used improved definitions of the furniture types to add precision and reduce ambiguity. For example, the category "small tables" was changed to "tables with 4 or fewer seats."

\section{Findings}

The resulting data were well-organized and multifaceted. Despite being a relatively simple and quick collection method, the data were rich enough to identify both building-wide trends and room-level furniture use patterns.

The library has four floors with user spaces, but most seats in the library are located on the second floor (77\%). There are eight major types of seating in Walter Library but the most common types of seating are at long, sturdy wooden tables found in the reference room and quiet study room (38\%) and soft chairs throughout the building (21\%).

The afternoon (3:00 p.m.) count is consistently the time of day when most seats in the library are occupied (Figures la and $\mathrm{lb}$ ). More seats are occupied at 3:00 p.m. on average than any other time. This is true for the building as a whole and for each section of the building, except for the basement in fall 2017. 
Figure 1a: Average occupancy rates (fall 2017)

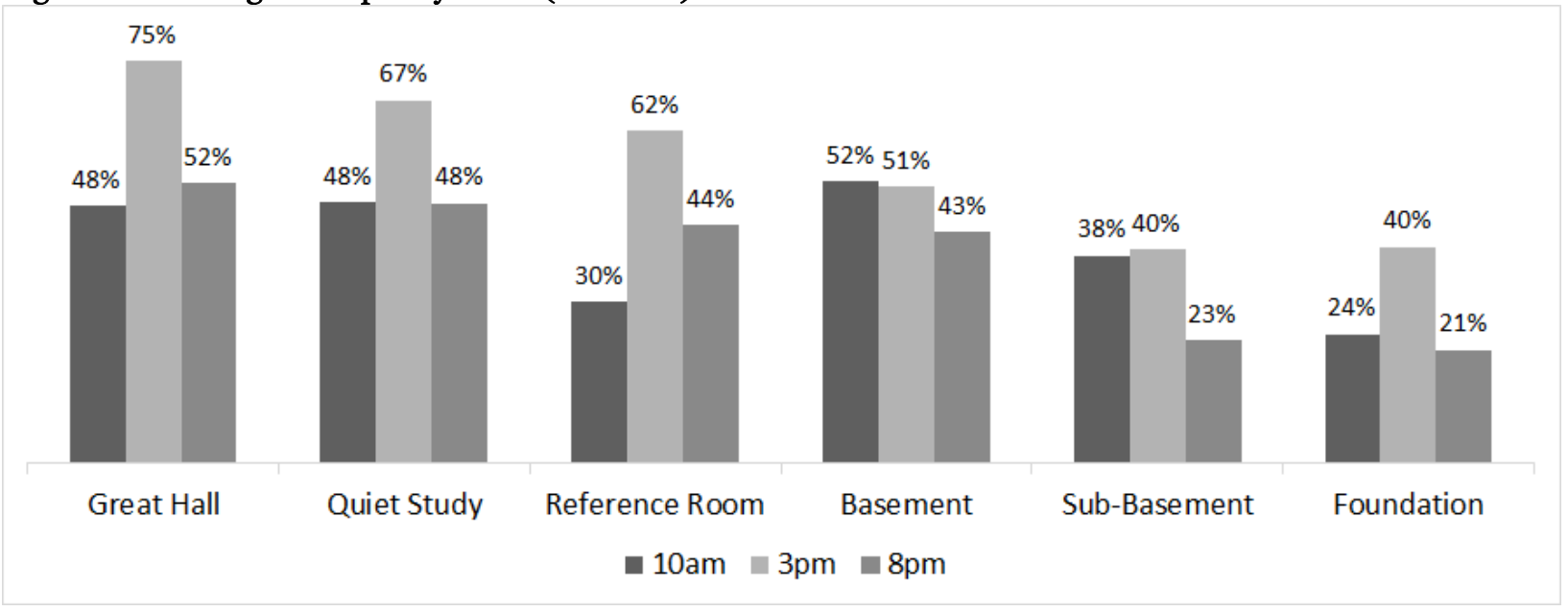

Figure 1b: Average occupancy rates (spring 2018)

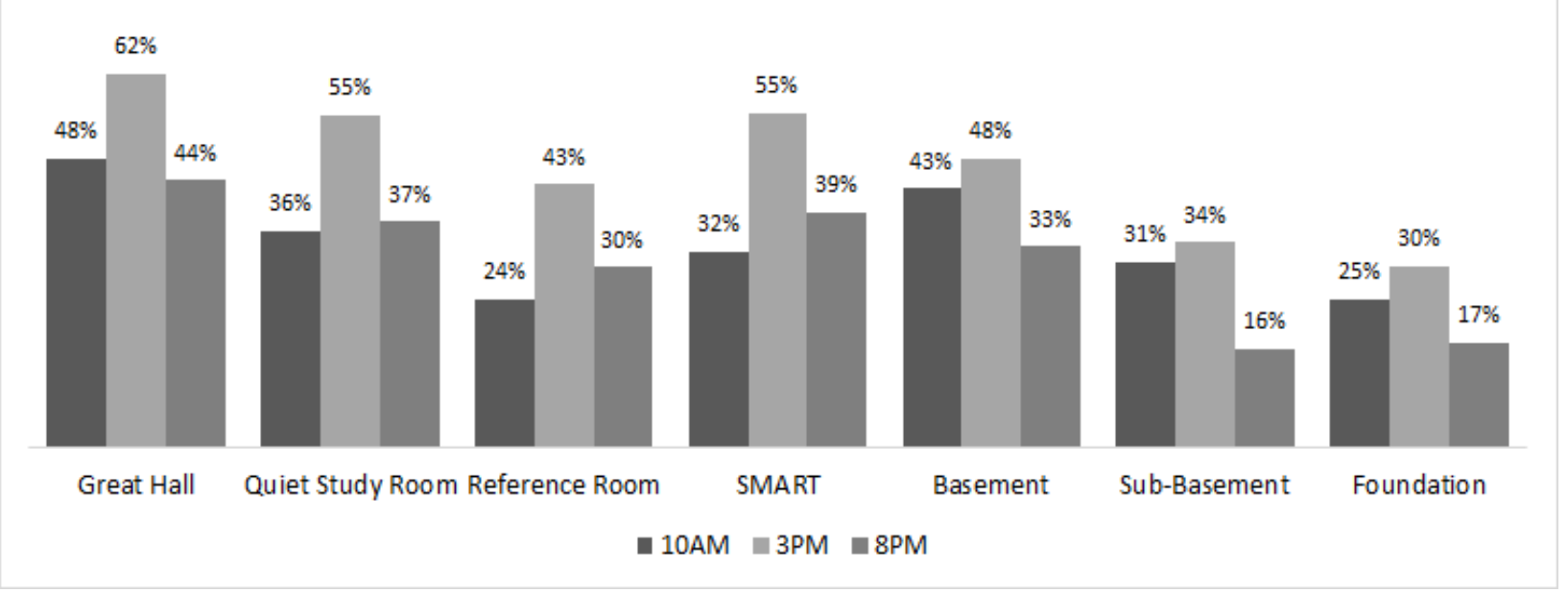

No area of the library was ever completely full at the time of the counts (Figures $2 \mathrm{a}$ and $2 \mathrm{~b}$ ). The highest percentage of occupied seats in any of our spaces was 84\% in the Great Hall during one count in the fall 2017 semester. Even then, there were a few seats available. 
Figure 2a: Max, min, and average occupancy rates (fall 2017)

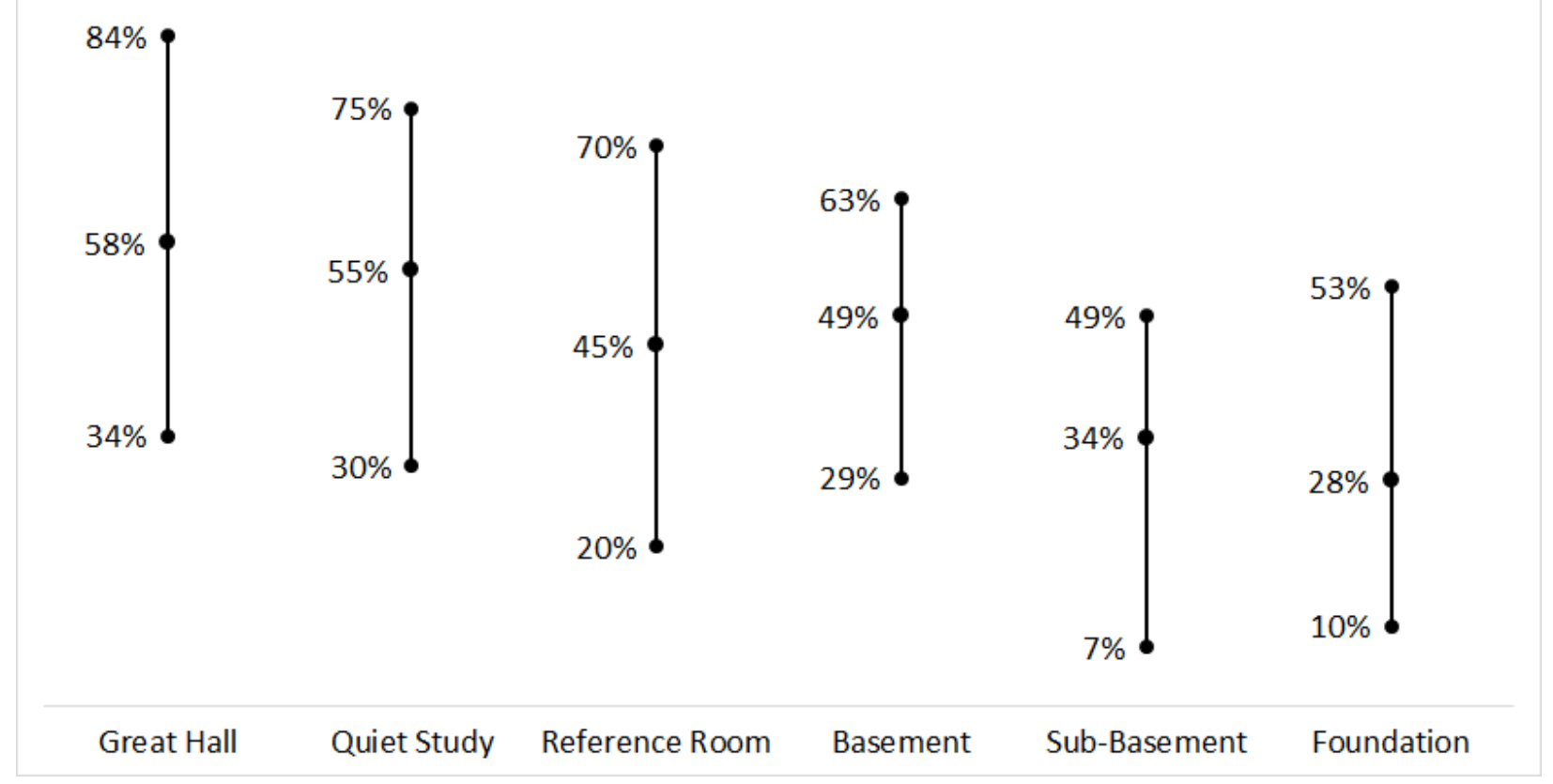

Figure 2b: Max, min, and average occupancy rates (spring 2018)

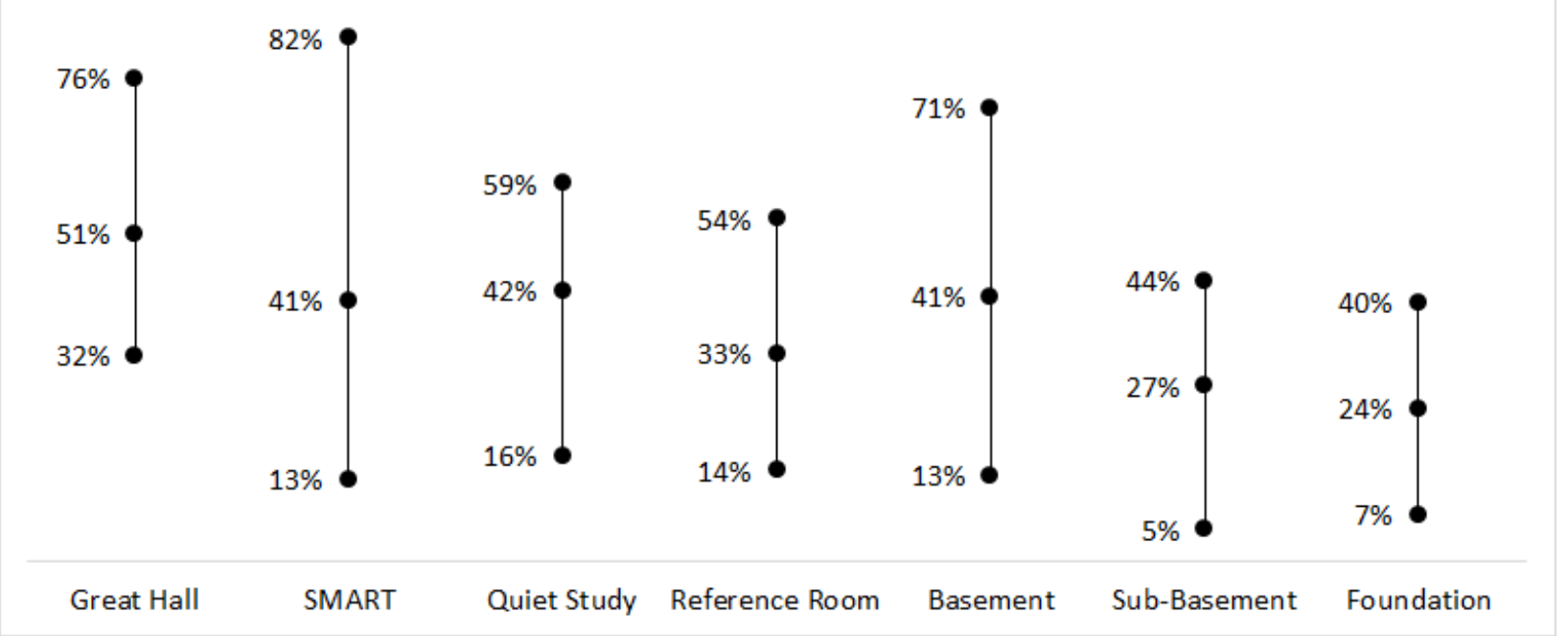

Extreme patterns of use were noted: furniture types in certain areas that were extremely heavily used or extremely underused. For example, the foundation level has several tables that seat 5-6 people each (Figure 3). These pieces of furniture were underutilized and were mostly empty for most of the counts. 
Figure 3: Foundation-level tables (fall 2017 and spring 2018)
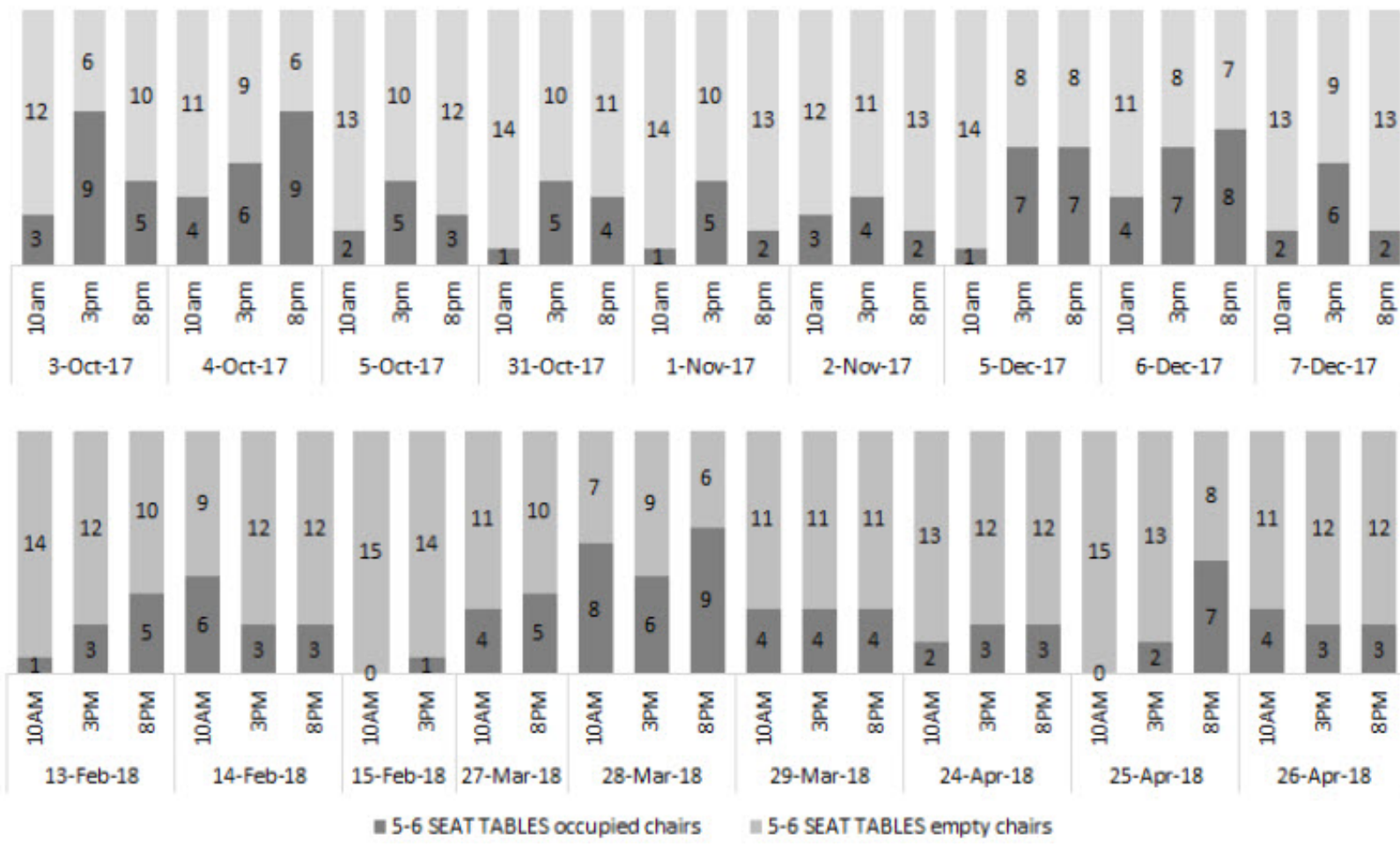

Another extreme use was a small group of soft chairs located in the quiet study room (Figure 4). The only time they were really heavily occupied was during the busiest afternoon counts when the other furniture in the room was crowded. However, in $85 \%$ of the counts in the fall semester, at least four or more chairs were empty. 
Figure 4: Quiet study room soft chairs (fall 2017 and spring 2018)
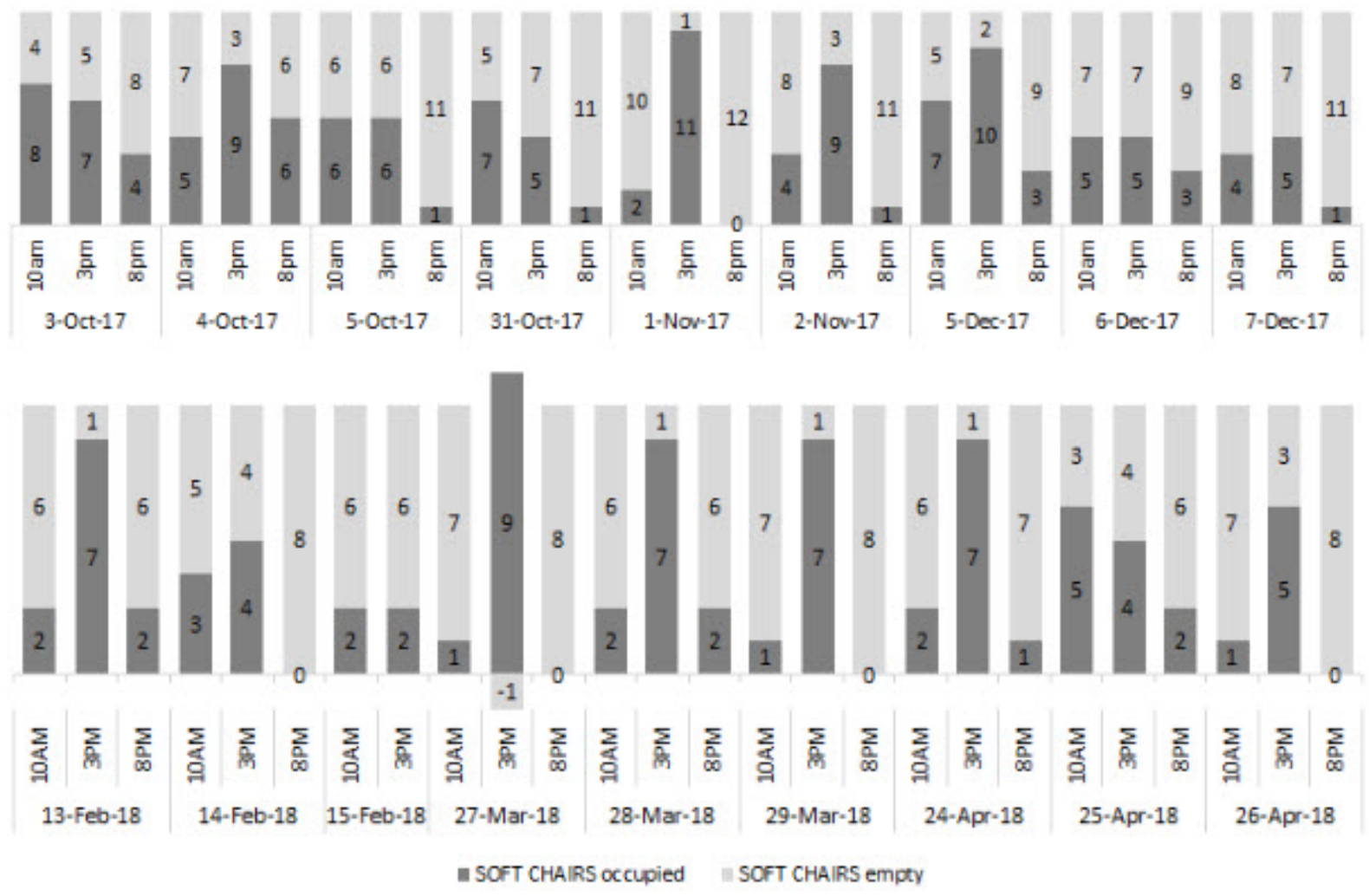

On the other end of the spectrum a cluster of individual study carrels in the quiet study room were heavily used regardless of time of day or time of the semester (Figure 5). Study carrels in other areas of the library were not as heavily used. 
Figure 5: Quiet study room carrels (fall 2017 and spring 2018)
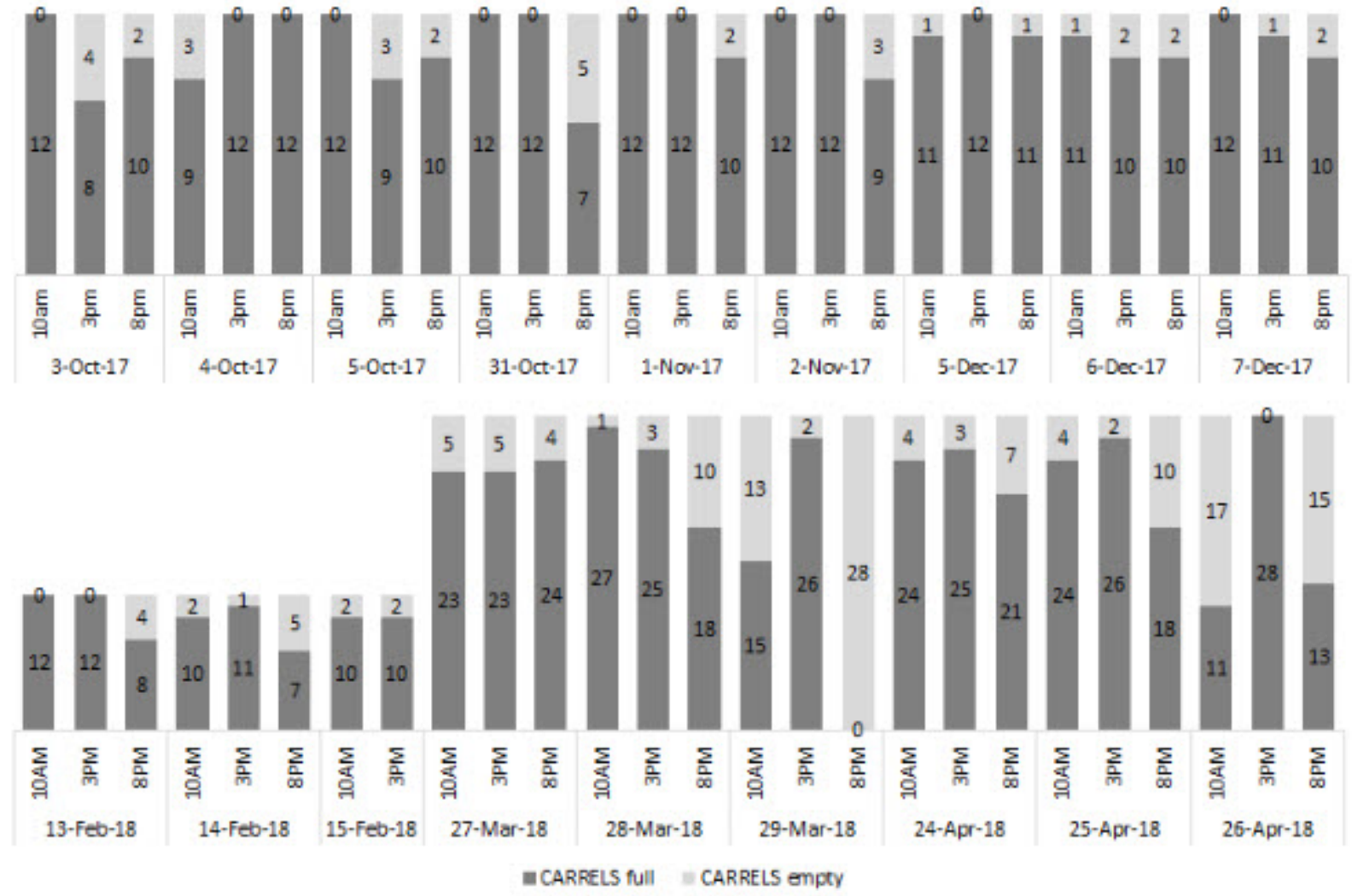

Groups of students were observed working throughout the building but they were often concentrated in the Great Hall. The Great Hall has 62 seats: 54 soft chairs and 8 seats at two small tables. Three or more groups were observed in $52 \%$ of the counts in the fall semester and $46 \%$ of the counts in the spring (Figure 6 ). Additional qualitative observational data showed that students pulled together clusters of soft chairs, grabbed mobile white boards, and made small collaborative spaces for themselves within the larger space of the Great Hall. 
Figure 6: How often groups were counted in the Great Hall
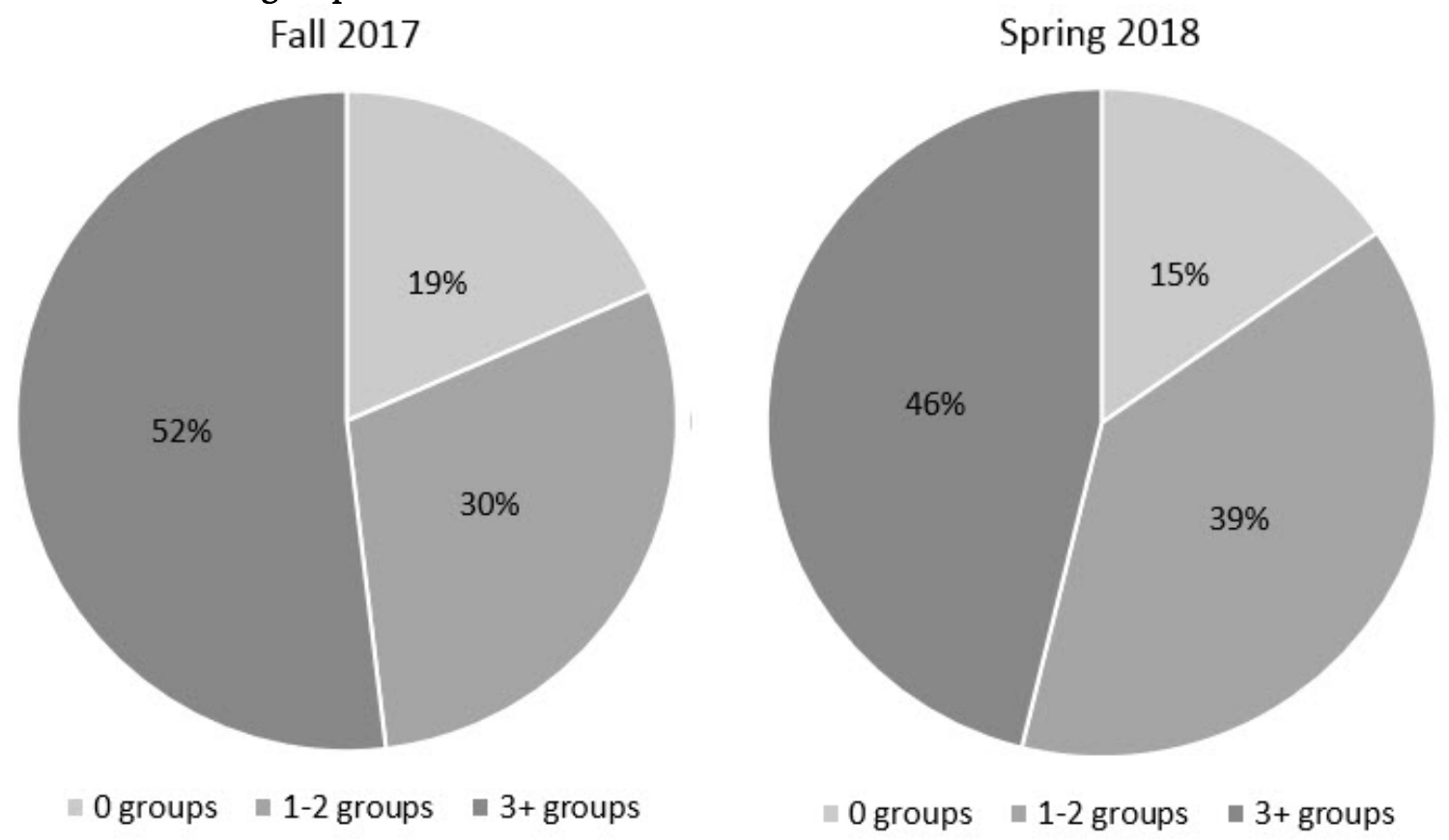

\section{Implications}

This lightweight space assessment method was created to provide detailed enough information to enable evidence-based decision-making, but not so complex or time-consuming that staff would not want to participate in data collection or feel ill-equipped to analyze or use the data. The descriptive headcounts are a simple form of space assessment that library staff can complete in under thirty minutes. The method produces data that a staff member with intermediate Excel skills can explore and transform into a story. The added metadata about furniture type, room, time, and group activity provides a balanced level of granularity to the data. The data can answer big picture questions about library use and inform individual decisions about the arrangement, location, and amount of furniture in a space.

Because the headcounts are flexible and lightweight, this study is repeated each semester. This routine allows us to gather large volumes of data and process them at a manageable rate. Since data is constantly being collected, incremental changes can be made to the instrument. Our collection methods have improved while retaining the ability to compare data across time.

Implementing this study has led to a shift toward creative, flexible, user-centered thinking. Walter Library has significant constraints on space design because of the historical status, large rooms, and heavy furniture that is expensive and difficult to move. With those constraints, it can be hard to imagine a simple first step to improve a space, much less a vision for the building. The headcount data has given us the freedom to focus on areas where small improvements can be made and subsequently assessed. Data focused on headcounts provides a sense of how users are interacting with the space, including what furniture they prefer or avoid. Decisions can then be made based on evidence and not assumption.

The field of environmental psychology can provide insight into some of the user behavior observed in the space. Studies have shown that people will seek out privacy and personal space and prefer to maximize the space between them and the next person unless they know one another. ${ }^{10}$ These findings provide a compelling explanation for why average occupancy rates hover around $50 \%$ in many of our library spaces, particularly spaces like the reference room and quiet study room that feature large tables without the 
defined personal space that soft chairs and study carrels offer. It also adds to understanding why users are so drawn to certain types of library furniture, particularly types that provide semiprivate personal space.

Some of the furniture-level information the data provided was so compelling that changes were immediately made to a space. Data was collected during both peak and off-peak times as recommended by Gullickson, et al. to provide a fuller picture of furniture use.$^{11}$ For instance, students who used the quiet study room space flocked to furniture that was designed for individual study but they did not use the available soft chairs except during the absolute busiest times of day, implying that soft seating in the quiet study room was not preferred and was likely being used because there was no other available seating. However, the soft chairs were used regularly for collaborative work in the Great Hall. As a result, the soft chair arrangement of seating was expanded to the reference room to discover whether students were willing to collaborate in a traditionally quiet space, taking the pressure off other crowded collaborative spaces in the library.

It was noted that tables in the foundation level were underused. Over the summer the tables were moved to the reference room on the second floor, while microform cabinets taking up valuable space in the reference room were moved down to the foundation.

This study put staff in touch with all the user spaces in the library and directly contributed to a shared vision for Walter's spaces. The counts provide several staff members and students with first-hand experience walking through the entirety of the library with the job of observing. Since the assessment does not take a lot of time, one person can do a count for the whole building on their own. The vision is a product of the combined stories the data tell us about what users value in our spaces with our individual observations and experiences conducting the headcount. An understanding of the library as a whole enables the imagining of how the library could evolve. The study highlighted the importance to our users of both communal study areas and collaborative social study areas. The vision articulates a desire to expand areas that serve each of these needs and turn underused and mixed-use spaces to spaces that fully support one type of studying.

The method we used limits our ability to understand why people are using certain furniture in our spaces or the reasons they prefer one area over another. Qualitative data from surveys, interviews, or focus groups would provide explanations and enable comparisons. To interpret the findings, information from the disciplines of environmental psychology, user experience, and learning theory have been helpful. While the methods are generalizable, the findings are very specific to our space. We are currently applying these methods to branch libraries in the same area of campus. In the future, we want to know how the library space compares to other study spaces on campus; what unmet needs our students have; and what our students and instructors expect of library spaces.

-Copyright 2019 Katherine Gerwig and Carolyn Bishoff

1. Gifford, Research Methods.

2. Applegate, "The Library is for Studying," 341-346; Leckie, Given, and Buschman, Critical Theory for Library and Information Science; Gullikson and Meyer, "Collecting Space Use Data"; Fox and Doshi, "Longitudinal Assessment of 'User-Driven' Library Commons Spaces,” 85-95.

3. Sandy, Krishnamurthy, and Scalfani, "Repurposing Space in a Science and Engineering Library," 388-393; Given and Archibald, "Visual Traffic Sweeps," 100-108.

4. Dominguez, "Beyond Gate Counts," 321-28; Fox and Doshi, "Longitudinal Assessment of 'User-Driven' Library Commons Spaces;" Holder and Lange, "Looking and Listening: A Mixed-Methods Study of Space Use and User Satisfaction," 4-27. 
5. Fox and Doshi, "Longitudinal Assessment of 'User-Driven' Library Commons Spaces”; Cha and Kim, "What Matters for Students' Use of Physical Library Space?" 274-79; Harrop and Turpin, “A Study Exploring," 58-77.

6. Andrews, Wright, and Raskin, "Library Learning Spaces," 647-72.

7. Aiello, "Human Spatial Behavior," 389-504.

8. Given and Leckie, "'Sweeping" the Library," 365-85.

9. Gayton, “Academic Libraries: 'Social' or 'Communal?', , 60-66.

10. Aiello, "Human Spatial Behavior."

11. Gullikson and Meyer, "Collecting Space Use Data to Improve the UX of Library Space."

Bibliography

Aiello, J.R.. "Human Spatial Behavior.” In Handbook of Environmental Psychology 1, edited by I. Altman \& D. Stokols, 389-504. New York: Wiley, 1987.

Andrews, Camille, Sara E. Wright, and Howard Raskin. "Library Learning Spaces: Investigating Libraries and Investing in Student Feedback.” Journal of Library Administration 56, no. 6 (August 17, 2016): 64772. https://doi.org/10.1080/01930826.2015.1105556.

Applegate, Rachel “The Library Is for Studying: Student Preferences for Study Space.” The Journal of Academic Librarianship 35, no. 4 (2009): 341-46. https://doi.org/10.1016/j.acalib.2009.04.004.

Cha, Seung Hyun, and Tae Wan Kim. "What Matters for Students' Use of Physical Library Space?" Journal of Academic Librarianship 41, no. 3 (2015): 274-79. https://doi.org/10.1016/j.acalib.2015.03.014.

Dominguez, Gricel. "Beyond Gate Counts: Seating Studies and Observations to Assess Library Space Usage." New Library World 117, no. 5/6 (May 9, 2016): 321-28. https://doi.org/10.1108/NLW-08-2015-0058.

Fox, R, and A Doshi. “Longitudinal Assessment of ‘User-Driven' Library Commons Spaces.” Evidence Based Library and Information Practice 8, no. 2 (2013): 85-95. https://doi.org/10.18438/B8761C.

Gayton, Jeffrey T. “Academic Libraries: 'Social' or 'Communal?' The Nature and Future of Academic Libraries.” Journal of Academic Librarianship 34, no. 1 (2008): 6066. https://doi.org/10.1016/j.acalib.2007.11.011.

Gifford, Robert. Research Methods for Environmental Psychology. Chichester, West Sussex, UK ; Malden, MA, USA: Wiley Blackwell, 2016.

Given, Lisa M., and Heather Archibald. "Visual Traffic Sweeps (VTS): A Research Method for Mapping User Activities in the Library Space.” Library \& Information Science Research 37, no. 2 (April 2015): 100108. https://doi.org/10.1016/j.lisr.2015.02.005.

Given, Lisa M., and Gloria J. Leckie. “'Sweeping” the Library: Mapping the Social Activity Space of the Public Library." Library and Information Science Research 25, no. 4 (2003): 36585. https://doi.org/10.1016/S0740-8188(03)00049-5.

Gullikson, Shelley, and Kristen Meyer. "Collecting Space Use Data to Improve the UX of Library Space.” Weave: Journal of Library User Experience 1, no. 5 (2016). http://dx.doi.org/10.3998/weave.12535642.0001.502. 
Harrop, Deborah, and Bea Turpin. "A Study Exploring Learners” Informal Learning Space Behaviors, Attitudes, and Preferences.” New Review of Academic Librarianship 19, no. 1 (January 2013): 5877. https://doi.org/10.1080/13614533.2013.740961.

Holder, Sara, and Jessica Lange. "Looking and Listening: A Mixed-Methods Study of Space Use and User Satisfaction." Evidence Based Library and Information Practice 9, no. 3 (2014): 4-27.

Leckie, Gloria J., Lisa M. Given, and John Buschman. Critical Theory for Library and Information Science: Exploring the Social from across the Disciplines. Santa Barbara, California; Denver, Colorado; Oxford, England: 2010.

Sandy, John H., Mangala Krishnamurthy, and Vincent F. Scalfani. "Repurposing Space in a Science and Engineering Library: Considerations for a Successful Outcome.” The Journal of Academic Librarianship 40, no. 3-4 (2014): 388-393, doi.org/10.1016/j.acalib.2014.03.015. 